\title{
ACHYROCLINE MACELLA (ASTERACEAE-GNAPHALIEAE), NOVA ESPÉCIE DO BRASIL ${ }^{1}$
}

\author{
LEONARDO PAZ DEBLE² JOSÉ NEWTON CARDOSO MARCHIORI ${ }^{3}$
}

\section{RESUMO}

Em recente revisão do gênero Achyrocline (Less.) DC. no Brasil, comprovou-se a existência de uma nova espécie - Achyrocline macella Deble \& Marchiori-, que é aqui descrita e ilustrada. Relacionada a Achyrocline hyperchlora Blake, A. gertiana Deble \& Marchiori e $A$. glandulosa Blake, a nova espécie também apresenta pêlos glandulares visíveis nas folhas. Essas três espécies são comentadas e diferenciadas do novo táxon. Palavras chave: Achyrocline macella, Gnaphalieae, Asteraceae, nova espécie.

\section{ABSTRACT}

In a recent review of the genus Achyrocline (Less.) DC. in Brazil, a new species was discovered-Achyrocline macella Deble \& Marchiori -, that is here described and illustrated. Closely related to Achyrocline hyperchlora Blake, A. gertiana Deble \& Marchiori and A. glandulosa Blake, the new species also have conspicuous glandular hairs on the leaves. This three taxa are commented and set apart from the new species.

Key words: Achyrocline macella, Gnaphalieae, Asteraceae, new species.

\section{INTRODUÇÃO}

Achyrocline (Less.) DC. compreende 35 espécies sul-americanas (Deble \& Marchiori, inéd.), que são muito próximas entre si e de difícil separação. Com a presente descrição, eleva-se a quatro o número de espécies providas de pêlos glandulares visíveis, nas folhas.

\section{DESCRIÇÃO}

\section{Achyrocline macella Deble \& Marchiori, sp. nov.}

TIPO - BRASIL, Paraná, Rio Branco do Sul, Caverna dos Bromados, 1,5 m de altura, flores amarelas, G. Tiepolo \& A. C. Svolenski 698, 16.VIII.1996 (MBM 209.409).

Suffrutex ramosus, $40-150 \mathrm{~cm}$ altus, caulibus adscendentibus, teretibus, dense incano-tomentosis. Folia alterna (internodiis 1,5-5 cm), sessilia, elliptica, discolora, supra glandulosa, subtus dense lanosa, apice acuta vel acuminata, basi attenuata, 1-6 cm longa, 0,2$1,2 \mathrm{~cm}$ lata. Capitula multa, cymoso-paniculata glomerata disposita. Involucrum auratum, cylindraceum, 5-5,5 mm altum, $2 \mathrm{~mm}$ crassum. Bracteis involucralibus 12-13; externis ovato-lanceolatis, acutis, 3-3,5 mm longis, 1,5 mm latis, dorso cum pilis lanosis et glandulosis, stereomate
$0,5 \mathrm{~mm}$ alto; mediis et intimis oblongis, obtusis vel acutis, 4,5 mm longis, 0,8-1,2 $\mathrm{mm}$ latis, dorso cum pilis glandulosis, stereomate 1,5-2,5 mm alto. Flores lutei, dimorphi: marginales 4-6, feminei, corolla filiforme, 3,8 mm longa, apice 4-dentata, dentibus deltoides, $0,05 \mathrm{~mm}$ longis, cum pilis glandulosis; stylo 3,5-4 mm; rami cum 1 $\mathrm{mm}$, apice truncati, papillosi; flores disci 1-2, hermaphroditi, corolla tubulosa, 3,8 mm longa, 5-dentata, dentibus deltoides, 0,3 mm longis, cum pilis glandulosis; antherae 1,8 $\mathrm{mm}$ longae, caudatae; caudae elongatae, barbatae, apice oblongo-trigonae, subacutae. Achaenia ovata-oblonga, 0,8 mm longa. Pappus albus, setae 3,53,8 mm longae; cellulis apicalibus obtusis, basi patentibus.

Subarbusto ramoso, com 40-150 cm de altura; ramos cilíndricos, ascendentes, densamente incano-tomentosos (Figura 1a). Folhas alternas (entre-nós de 1,5-5 cm), sésseis, elípticas, de 1$6 \mathrm{~cm}$ de comprimento por $0,2-1,2 \mathrm{~cm}$ de largura, discolores, densamente lanosas na face abaxial e glandulosas na adaxial, de margens íntegras, ápice agudo ou acuminado e base atenuada (figura 1a'). Capítulos numerosos, amarelo-dourados, em cimas de glomérulos compondo panículas mais ou menos amplas (Figura 1a).

1 Artigo recebido em 09/01/2006 e aceito para publicação em 02/02/2006.

2 Biólogo, Msc., bolsista CAPES, doutorando do Programa de Pós-Graduação em Engenharia Florestal, Centro de Ciências Rurais, Universidade Federal de Santa Maria. CEP 97105-900, Santa Maria (RS). deble.biol@bol.com.br

3 Engenheiro Florestal, Dr., bolsista de Produtividade em Pesquisa do CNPq, Professor Titular do Departamento de Ciências Florestais, Universidade Federal de Santa Maria. CEP 97105-900, Santa Maria (RS). balduinia@mail.ufsm.br 
Invólucro cilíndrico, de 5-5,5 $\mathrm{mm}$ de altura e 2 $\mathrm{mm}$ de diâmetro (Figura 1b). Brácteas involucrais, 12-13; as externas, ovadolanceoladas (3-3,5 mm de comprimento por 1,5 $\mathrm{mm}$ de largura), agudas no ápice, com pêlos lanosos e glandulares no dorso e estereoma de 0,5 $\mathrm{mm}$ (Figura 1e); as medianas e internas, oblongas (4,5 mm de comprimento por $0,8-1,2$ $\mathrm{mm}$ de largura), obtusas ou agudas no ápice, com pêlos glandulares no dorso e estereoma de 1,5$2,5 \mathrm{~mm}$ (Figura 1e). Flores dimorfas. As marginais, 4-6, femininas e filiformes, com corola de $3,8 \mathrm{~mm}$ de comprimento e ápice 4-dentado (Figura $1 \mathrm{c})$; dentes deltóides $(0,05 \mathrm{~mm})$, com pêlos glandulares; estigma de 3,5-4 mm, com ramas de $1 \mathrm{~mm}$, truncadas e papilosas no ápice. Flores do disco, 1-2, hermafroditas, com corola de 3,8 $\mathrm{mm}$ de comprimento, 5-dentada no ápice; dentes deltóides $(0,3 \mathrm{~mm})$, com pêlos glandulares (Figura 1d); anteras de 1,8 mm, com caudas alongadas, fimbriadas e ápice oblongotriangular, levemente agudo. Aquênios ovadooblongos, de $0,8 \mathrm{~mm}$ de comprimento (Figura 1f). Pápus branco; cerdas de 3,5-3,8 mm de comprimento, com células apicais obtusas e basais patentes.

Paratypi: BRASIL: BAHIA: Esplanada, fazenda do Bu Mata do Fundão II, erva ereta de caule viloso, Floresta Ombrófila Aberta, T. Jost \& M. C. Ferreira 391, 10.IX.1996 (MBM 285.557). Mucugê, Unidade de Manejo Sustentável, subarbusto cerca de $70 \mathrm{~cm}$, freqüente, afloramento rochoso e areia, H. P. Bautista \& S. L. Silva, 06.IV.1997 (MBM 216.966). Palmeiras, Capão Grande, no sentido de Cachoeira da Fumaça, N. Hind \& L. P. Queiroz, 29.X.1996 (MBM 272.599); Campo São João, leito do rio sem nome, completamente seco, $12^{\circ} 27^{\prime} 8^{\prime \prime} \mathrm{S}$ $41^{\circ} 29^{\prime} 17^{\prime \prime} \mathrm{W}$, arbusto 1-2 m, T. S. Nunes 198, M. J. Lemos \& E. R. Souza, 23.X.2000 (HUEFS 49.435, MBM 283.593). Piatã, boca da mata, $80 \mathrm{~cm}$ alt., folhas papiráceas, H. P. Bautista \& D. J. N. Hind, 12.XI.1996 (MBM 272.598). DISTRITO FEDERAL: Brasília, Parque da Gama, 45 km S of Brasília, 1000 m.s.m., P. H. Davis 60.167, 12.VII.1976 (MBM 52.032). MINAS GERAIS: Itamonte, próximo à divisa com o estado do Rio de Janeiro, M. R. Ritter 925, 27.VII.1996 (ICN 112.278). Jequitinhonha, Serra de Areia, $47 \mathrm{~km}$ ao sul da Pedra
Azul, campo rupestre e cerrado de altitude, R. M. Harley et al.25.278, 20.X.1988 (MBM 151.357). Viçosa, I. Mefia, 31.VII.1930 (MBM 82.282). RIO DE JANEIRO: Nova Friburgo, estrada Rio de Janeiro-Nova Friburgo, próximo à cidade de Nova Friburgo, M. R. Ritter 919, 24.VII.1996 (ICN 112.277). Passa Três, Z. A. Trinta 863 \& E. Fromm 1939, 19.IX.1964 (BR).

Etimologia: o epíteto específico origina-se do nome popular atribuído à espécie: macela.

Distribuição \& Habitat: Espécie exclusiva do Brasil, ocorre principalmente nos estados do nordeste e sudeste do país. Floresce e frutifica com maior frequiência ao final do inverno e na primavera.

Comentários: Achyrocline macella distingue-se pelas folhas discolores, com a face adaxial coberta de pêlos glandulares. Demonstra afinidade com Achyrocline gertiana; as folhas, todavia, são elípticas, os capítulos, amarelo-dourados, apresentam 12-13 brácteas involucrais, e as flores femininas possuem corola de $3,8 \mathrm{~mm}$, com dentes de $0,05 \mathrm{~mm}$. Achyrocline gertiana apresenta folhas elíptico-lanceoladas, capítulos estramíneos com 16-18 brácteas involucrais e flores femininas com corola de 4,5-4,8 mm, com dentes de 0,2 mm. De Achyrocline hyperchlora, separa-se pela coloração e maior tamanho dos capítulos, pelo maior número de flores, bem como pela disposição da capitulescência. Achyrocline hyperchlora apresenta capítulos de coloração parda até marfim, com apenas 4-5 flores e capitulescência disposta ao longo dos ramos superiores. Achyrocline macella também se aproxima de $A$. glandulosa, da qual separase pelo hábito e pelas folhas discolores, não decurrentes.

\section{BIBLIOGRAFIA}

Deble, L. P., Marchiori, J. N. C. Novidades em Achyrocline (Less.) DC. (Asteraceae-Gnaphalieae). Balduinia, Santa Maria, n. 3, p. 10-13, 2005.

Deble, L. P., Marchiori, J. N. C. Revisão das espécies brasileiras do gênero Achyrocline (Less.) DC. Balduinia, Santa Maria (no prelo). 


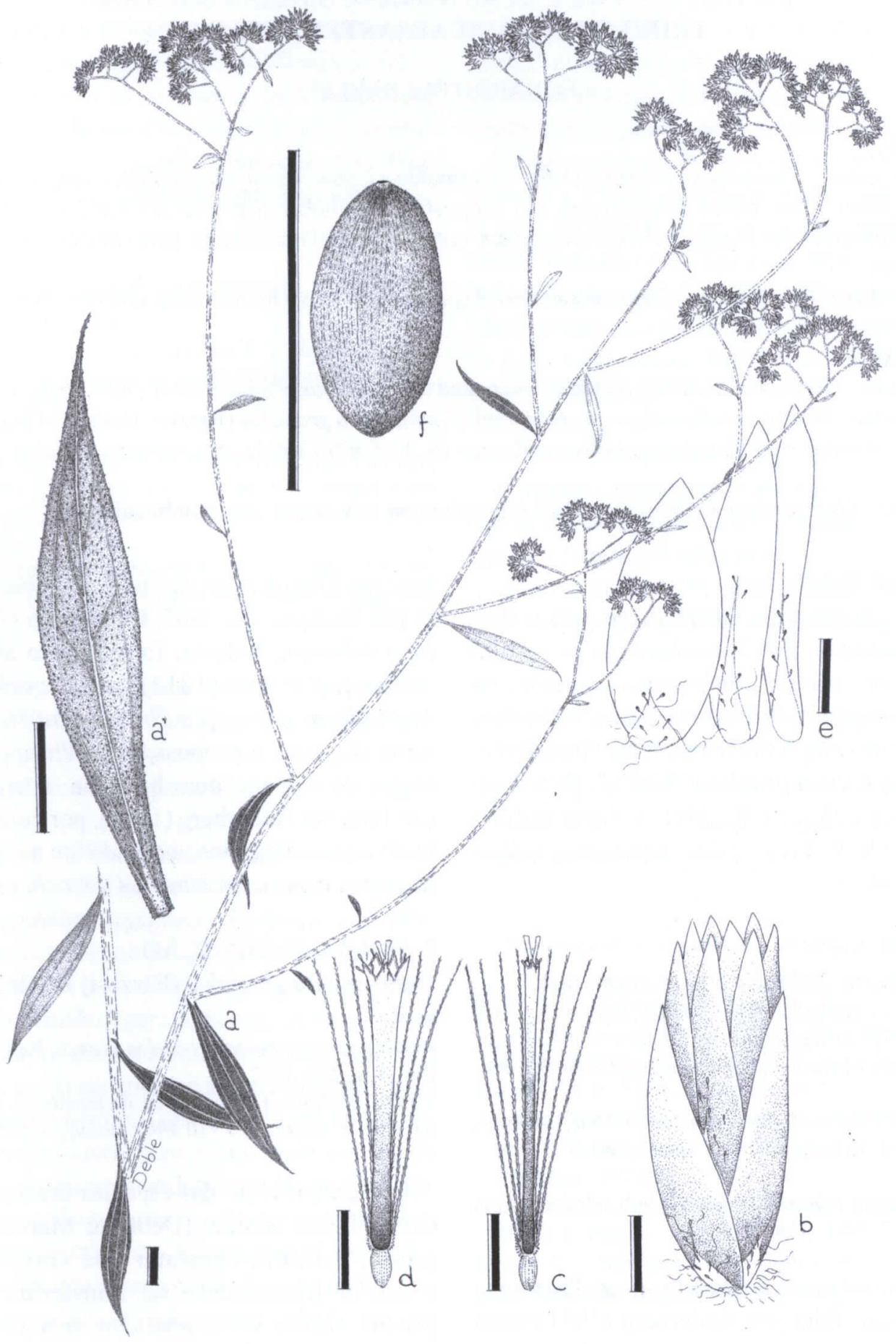

FIGURA 1 - Achyrocline macella Deble \& Marchiori. Ápice do ramo florífero (a). Folha (a'). Capítulo (b). Flor marginal (c). Flor do disco (d). brácteas involucrais (e). Aquênio (f). Escala a, a' = 1cm; b, c, d, e, f= $1 \mathrm{~mm}$. 